\title{
Interaction between industry higher educational institutions and the customer of educational services
}

\author{
Valentina Parshina, ${ }^{1, *}$, and Elena Kuznetsova ${ }^{2}$ \\ ${ }^{1}$ Ural State University of Railway Transport; 66 Kolmogorova st., 620034, Ekaterinburg, Russia \\ ${ }^{2}$ Ural Federal University, 19, Mira str., room M-521, Ekaterinburg, Russia
}

\begin{abstract}
The purpose of the article is to develop a model for interaction between industry higher educational institutions and the customer of educational services in order to increase the human potential in the industry. The article deals with the specifics of relations between the transport higher educational institutions and the company. To assess the quality of relations, the resource exchange model is suggested for use. The article formulates principles of interaction between the parties and indicators that can be used to assess the quality of the resources exchange. A model for interaction between the company's business units and higher educational institutions was proposed. The relations between the horizontal-structured corporation and educational institutions were modeled; the mathematical apparatus was selected to describe the contacts, indicators of satisfaction with the resources and the resultant indicator (satisfaction with the interaction) were proposed. The model will help to determine quantitative characteristics of the achieved contacts. Their introduction will make it possible to assess the original state of the contacts and proceed to functional design. Introduction of the concept of satisfaction with the resources and interaction in its individual lines will allow identifying the reserves to build on in order to optimize the contacts. The purpose of the modeling is to expand contacts between the higher educational institution and enterprises in the industry, to involve employees in innovation activities, to improve skills of the higher educational institution graduates in response to the needs of the industry. This article only looks at the interaction between industry higher educational institutions and business units of RZD OJSC, whereas recent years brought contacts between the university and many transport organizations that have specifics of market interactions described in the stakeholder theory.
\end{abstract}

\section{Introduction}

The Russia's transition to the market economy has predetermined new interaction patterns when actors exchange resources belonging to them. Special conditions for coordination of the parties' interests are established between higher educational institutions and enterprises that use their services. The Russian Federation's specifics is availability of industry-specific

* Corresponding author: vparshina@usurt.ru 
education in many areas. Its advisability is evidenced by the fact that, in recent years, there has been a surge in the initiatives of large corporations to create their own universities that provide training of professionals, which is adapted to the activity area. The establishment of a mutually beneficial exchange of resources in such a specific environment as between industry higher educational institution and enterprises has not been described in the literature in such a way as to enable developing a model of effective relations between them.

Based on the available materials, we will summarize the features of functioning of the current industry-specific education system, with interrelation between higher educational institutions and employers (the main focus is placed on the specifics of transport higher educational institutions):

- above all, those are existing stable contacts between an industry higher educational institution and certain enterprises (in RZD OJSC, with a limited list of facilities);

- public administration often leading to unreasonable cutting of higher educational institutions' financial resources;

- economic conditions of state-owned corporations that do not contribute to development of local innovative research, which has affected the types of contacts with the higher educational institutions;

- traditionally (inertially) limited marketing activities of the higher educational institution in the sense of expanding contacts, for example, with small transportation companies;

- a long-standing set of interaction types, some of which require revitalization;

- for multiple reasons, formation of short-time planning horizons;

- the enterprise can directly express requirements to the higher educational institution about training of students, by assessing the end result: competences of graduates;

- a rigid management hierarchy in the industry;

- lack of industry-specific business units that would provide indicators and criteria of efficient interaction between the higher educational institutions and enterprises, carry out monitoring or develop the strategy;

- the real sector of economy showing low interest in cooperation with the higher educational institutions;

- the holding's strategic plans lack elements of development of the personnel training system;

- a substantial contradiction between a large volume of planned innovations in the industry and limited scientific relations with the higher educational institutions.

The notion of the features of interaction between industry higher educational institutions and employers, with rigid connections that differ from market relations between most universities with customers of educational services, suggests that the objectives of industrial development strategies require managing the cooperation between stakeholders.

The long-standing contacts (transport education system go back for more than 200 years) under dramatically changing operating conditions require constant monitoring of the external environment and developing adaptation mechanisms. As a proof-point of the relevance of such changes, we can cite a well-known theory of the features of management at each stage of the organizations' life cycle, and the need to consider the changes in the external environment when choosing the management objectives. Under changing external conditions, organizations have to develop a long-term behavior strategy that would enable to keep pace with the changes taking place in their surroundings. According to I. Adizes [1], at the current stage of the lifecycle it is advisable to strengthen and formalize the actors' interrelations horizontally. Let us use this conclusion as a starting point for the interaction development. On the higher educational institution's part, the process stakeholders include basic departments that train professionals who carry out research work for the industry, etc., 
and on the part of the enterprises, they include RZD's specific business units that employ graduates, etc. It means that the parties do have shared interests.

At the sectoral meetings and parliamentary hearings on education in the transportation area, it is pointed out [6] that recent years have not improved, but rather destroyed, the mutual respect and trust. To resume the mutual cooperation, it is necessary to regain understanding of the fact that both parties pursue common long-term interests. Note that ignoring interference in setting up the interaction leads to losing the potential of both of them.

The above arguments allow making a conclusion about the relevance of forming an organizational model of contacts based on the stakeholders' interests, to create a synergistic effect for better performance of the industry.

In recent years, foreign and Russian researchers have been showing interest to the theory of interaction $[2,5,8]$ for the purpose of obtaining a substantial effect in various areas: marketing, setting up the design process, interaction between organizations, sales, psychology of communication, etc. Some papers [3] describe interaction between the classic universities and stakeholders having their own features. In this aspect, there prevails a market mechanism of communication, which provides an opportunity to select stakeholders for cooperation on both sides, where employers are somewhat dissatisfied with the quality of training and, on the other hand, there is an opportunity to choose a higher educational institution. This makes the interaction model reasonable in terms of developing the indicators to be used for comprehensive assessment of the quality of contacts.

In Russia, the need for such structure of the higher education system is emphasized, where the competences of graduates will be most adequate to the needs of employers and companies. However, the current system of industry-specific education is facing hard times, as the conditions of interaction with the main customer of educational services (RZD) are mostly determined and initiated by it. At the same time, we should not play down a possibility of cooperation with small companies in the area. Such cooperation can be organized both by the higher educational institution and the business community. This aspect of contacts is not addressed herein.

The described initial conditions for the functioning of specific facilities (an industry higher educational institution and enterprises in the industry) allow proceeding to modeling the interaction between them in order to improve the performance of each of the parties and the industry as a whole.

Due to the differences in the performance assessment criteria for the higher educational institutions and RZD's enterprises, it does not seem possible to use quantitative economic indicators to evaluate the adequacy of the mutual exchange of resources. There is no profit indicator provided for the higher educational institutions, while ratings use such indicators as: the number of employed graduates, the number of faculty members with academic degrees, the volume of research work, the proportion of young people among faculty members, etc. This set of indicators indirectly reflects the training quality. In practice, this dependency is much more complex, and it is impossible to isolate the effect of each individual factor upon the level of competence of graduates. For example, the optimization of the higher educational institution's financial receipts is not a goal in itself but a means to educate students under the conditions of the limited public funding.

Our research of the quality of life of a transport higher educational institution faculty members and, above all, young workers [7], has made it possible to identify their priority needs and the degree of their satisfaction with the higher educational institution. Surveys showed that salary is placed first (it includes the salary itself and incentive payments for publications, research work, etc.) If the economic reward (which includes bonuses for participation of young people in various forms of joint innovative projects with RZD's enterprises) is low, they prefer production activities to working at the higher educational 
institution. At the same time, it should be pointed out that there is a high percentage prospective students making a quite informed decision about choosing a transport higher educational institution and planning to work in this area, as shown in Fig. 1. The data is based on surveys of the university entrants in 2018. Surveys show that further preferences of young people during both their studies and employment are associated with financial factors to a large extent.

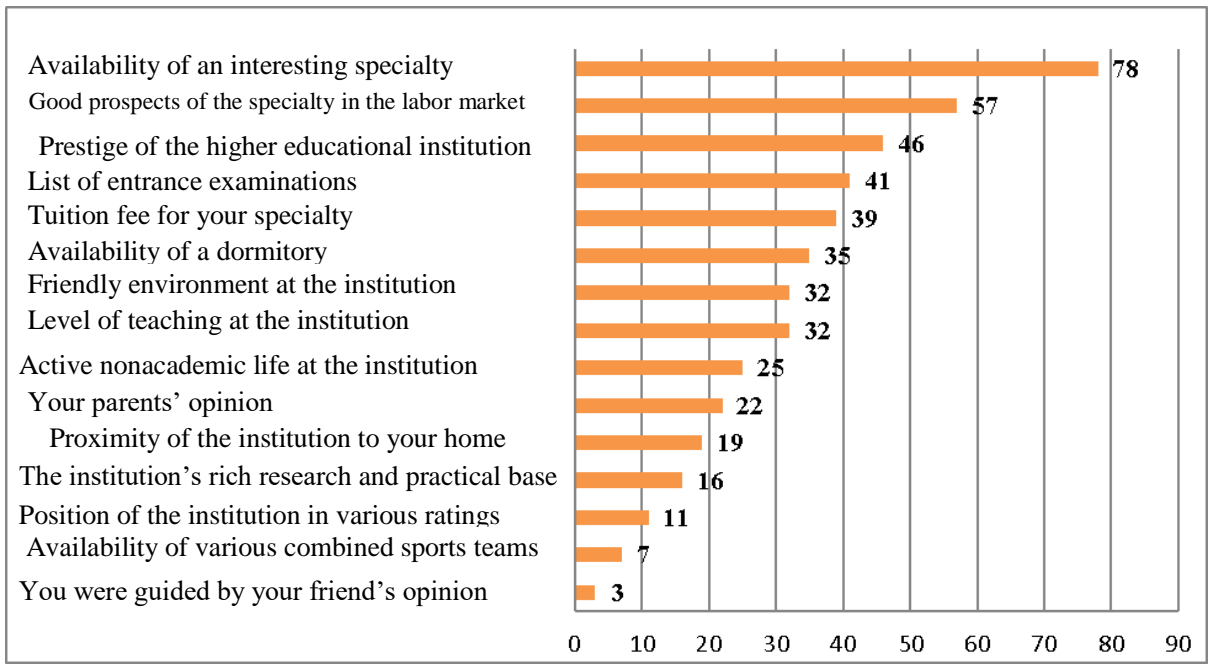

Fig. 1. Reasons for choosing a transport higher educational institution by prospective students.

On the part of the RZD's business units, the performance of the higher educational institution is largely determined by the competence of graduates who create the intellectual capital of the industry. In case they are dissatisfied with the quality of personnel training, they have to make additional costs for adaptation of young professionals, otherwise, there is a risk of underperformance. As a result, the competence of graduates is the principal qualitative indicator for interaction with the higher educational institutions sought-after by business units of the industry. However, with the established close interaction between industry higher educational institutions and business units in the industry, the training quality is determined by effective actions of both parties.

The goal of modeling of the interaction involves the interests of both parties. We suggest using a model based on the following principles (the materials of [10] were used and adjusted to the area under study):

- equal responsibility of the industry higher educational institution and business units of the company for personnel training;

-interest and involvement of the company's representatives in all areas of the professionals training;

- creation of a corporate structure to ensure the interaction;

- appreciation, by the employer, of priority of the training process that creates the industry's human capital to operational training;

- catering to the students' interests as much as possible.

For assessment of awareness of the importance to respect the parties' interests and carry out monitoring, we will first formalize the key performance indicators used in the interaction.

The interaction quality can be assessed using an expert assessment method by each of the stakeholders. This approach is proved reasonable by the fact that, in case of 
dissatisfaction with the relations, the employees' motivation level and contacts weaken. And if horizontal contacts are initiated in the absence of organizational measures for adaptation, the effectiveness of the interaction goes down.

Several lines of joint activity of industry enterprises and higher educational institutions can be outlined. The following lines of interaction are suggested for the higher educational institutions' assessment by employers:

-employment assistance;

- industrial work placement at the company's business units;

-involvement in the learning process (giving lectures, coordination of topics of graduation and contest projects, participation in creating curricula and the work of State Examination Commissions, retraining, etc.);

- joint research;

- preparation for defense of dissertations;

- contest sponsoring;

- promotional activities, etc.

Each of those lines contributes to the formation of human capital in the industry. Presence of resource dependence means that efficiency of a higher educational institution depends on availability of certain resources, and the welfare of the industry depends on availability of qualified professionals. J. Frooman [11, p. 201] composed a typology of relationships between the actors. He characterized a certain type of relations (by making adjustments to the period and area of activity) as domination of service consumers, where they are oriented towards a strategy of holding on to resources. It should be emphasized that this situation entails additional costs and losses, and it is still to be determined which party is bearing a greater part of those.

The resource exchange theory covers a wide range of resources [9]: financial, information, human, tangible, intangible, production and technical, organizational and managerial, commercial, timing, administrative resources, etc. It is difficult to quantify every one of those; however, they are amenable to expert assessment. Unlike a traditional view of resources as something to spend during activities, the article looks at the profitability aspect of resources. In this case, it is reasonable to determine the most important resources and then assess the nature and quality of exchanging them in order to identify, analyze, and assess opportunities of coordination of the interests of the higher educational institution and the corporation's business units, develop managerial decisions based on the obtained results, and establish an interaction system. Fig. 2 shows the interaction layout for the exchange of resources. 


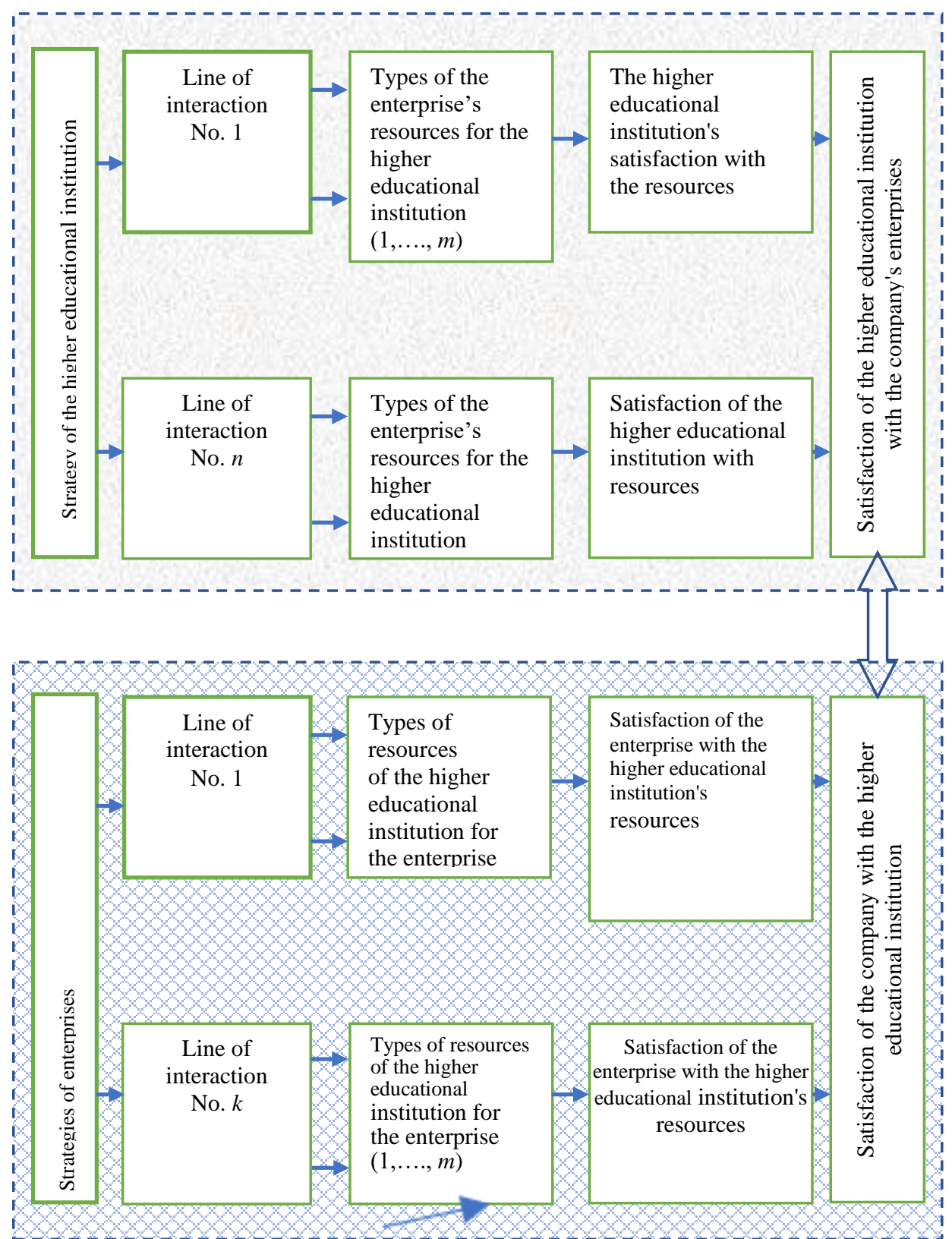

Fig. 2. A model of resource exchange between the higher educational institution and the company's business units.

The quantity and quality of resources obtained by each party are subject to change in time. It depends on the condition of organizations and, largely, on the company's general policy. 
To determine the resource contribution of each party into their joint work, we use an approach allowing to measure the volume, quality, promptness of the provided resources, etc. through verbal evaluations and then to translate those into the fuzzy sets.

Based on the industry-specific conditions of the interaction, we assessed the satisfaction of the higher educational institution workers with obtained resources, on the basis of selected criteria (quantity, quality, promptness) by the expert assessment method, in the following sequence:

- determination of lines of interaction;

- determination of a general list of analyzed resources during the interaction; list;

- selection of resources being assessed within the lines of interaction from their general

- selection of experts based on their competence and knowledge of specific areas;

- compiling questionnaires, carrying out surveys;

- determination of satisfaction with each resource (using the weighting factor) within the lines of interaction, and then with all obtained resources;

- calculation of the interaction level;

-identification of the main lines of improving the interaction efficiency.

For enterprises, the assessed areas of interaction include: skills of graduates, quality of graduation theses, quality of consulting and training services, advanced training courses, research work performed, etc. The assessment sequence is similar to the one outlined above.

It is proposed to use the expert assessments obtained during surveys of the higher educational institution and industry enterprises workers having systemic knowledge. It is suggested to measure satisfaction of both parties with the resources obtained on a scale from 0 to 10 (where 0 means that the higher educational institution (enterprise) has not obtained the resource or is definitely not satisfied with what it obtained, and 10 means that the higher educational institution (enterprise) is fully satisfied with the quality and quantity of the obtained resource).

Based on the experts' assessments, priority lines of interaction are calculated for the higher educational institution. Lines of interaction 1, ..., n (Fig. 2) apply to the higher educational institution and are used for the formation of expert groups within the lines of interaction (direct participants of a particular line of interaction). Lines of interaction $1, \ldots, \mathrm{k}$ apply to the company's business units and are used for surveying its employees.

Further, pairwise comparisons matrices are created for resources, based on their impact on achievement of the university's strategic goals. For each of them, a vector of priority of the resources obtained by the university is calculated. The number of pairwise comparisons matrices will correspond to the number of the lines of interaction. As a result, we obtain own vectors arranged by the columns of the priority matrix:

$$
X=\left(x_{i j}\right)_{n \times m}=\left(\begin{array}{cccc}
x_{11} & x_{12} & \cdots & x_{1 m} \\
x_{21} & x_{22} & \cdots & x_{2 m} \\
\vdots & \vdots & \vdots & \vdots \\
x_{n 1} & x_{n 1} & \cdots & x_{n m}
\end{array}\right)
$$

Then we determine the level of satisfaction of the higher educational institution with interaction with the RZD's business units as a result of general satisfaction with resources. If a certain resource is obtained by the higher educational institution through several lines of activity, the weight factor of this resource is divided between them proportionately to the amount of the used resource.

At the next stage, each business unit uses the same method to assess the level of satisfaction with the resources it obtains from the university. Representatives of the company who have systemic knowledge in various areas of activity act as experts. 
Satisfaction of the university with the obtained resources for each line of interaction will be determined as the weighted average of assessments by all experts. Based on the calculations, the total satisfaction with the resources obtained by the higher educational institution is determined, and it is equated to the satisfaction of the university with the company. Similarly, the level of satisfaction of business units with the higher educational institution can be calculated.

Determining measures of satisfaction with the interaction of both sides makes it possible to estimate the resource contribution of each party of the relations and use it to bring the volumes of the provided resources in balance, and this opens the opportunity for practical application of the resource interaction model to obtain an industry-wide effect.

This method is not limited to determining the impact of resources obtained by the university (or enterprises that provide those resources) on achieving its strategic goals. It becomes possible to forecast the activities that are provided with a certain amount of required resources, in terms of the interests of both parties. A coordination center for interaction between the parties will help to set up those processes.

\section{References}

1. I. Adizes, Managing Corporate Lifecycles (2014)

2. R.M. Grant,. Bulletin of St. Pet. Univ. Manag. 3, 47-75 (2003)

3. A.A. Gresko, S.S. Solodukhin, Models and Methods of Choosing Strategies of Interaction Between a University and Groups of Stakeholders under Conditions of Uncertainty (Vladivostok, IVGUES, 2014)

4. V.S. Katkalo, Evolution of the Strategic Management Theory. (St. Pet. SPbGU, 2006)

5. G.B. Kleiner, Russ. J. of Manag.3(9), 3-28 (2011)

6. V.A. Nikonov, Parliamentary Hearings. Strategy of Russia.9, 5-18 (2017)

7. V.S. Parshina, N.V. Kalganova, Management Issues 5, 132-138 (2017)

8. O.M. Smirnova, International Journal of Civil Engineering and Technology 9(8), 17331740 (2018)

9. V. Y. Alpatov, O. Y. Veremeenko, A. A. Sakharov, V. S. Shirokov, MATEC Web of Conferences 86, 02015 (2016). DOI: 10.1051/matecconf/20168602015

10. R.N. Fedosova., Y.A. Yurga, Bulletin of the Financial Academy 1-2, 87-92 (2006)

11. J. Frooman, Academy of Management Review 24(2), 191-205 (1999) 